\title{
Paisajes acuáticos. Escenas literarias sobre el Riachuelo de las primeras décadas del siglo $\mathrm{XX}^{2}$
}

\section{Aquatic landscapes. Literary scenes about the Riachuelo of the first decades of the 20th century}

\author{
Pilar Cimadevilla* \\ Instituto de Investigaciones Históricas y Sociales. Universidad Nacional \\ de la Patagonia San Juan Bosco \\ pilar_cimadevilla@yahoo.com.ar
}

\footnotetext{
2. Una versión preliminar del artículo fue presentada en las 1as. Jornadas de Investigación "Ríos urbanos: nuevas perspectivas para el estudio, diseño y gestión de los territorios fluviales". Facultad de Arquitectura y Urbanismo, Universidad Nacional de La Plata / Instituto de Arquitectura y Urbanismo, Universidad Nacional de San Martín, 2 y 3 de noviembre de 2017.

* Licenciada en Letras por la Facultad de Humanidades y Ciencias de la Educación de la Universidad Nacional de La Plata. Actualmente realiza el Doctorado en Letras en la misma Universidad financiada por una beca del CONICET. Su proyecto de tesis "Fotografía y plástica en las crónicas periodísticas de Roberto Arlt (1928-1942)" se enmarca en los estudios sobre literatura argentina e intermedialidad. Ha publicado artículos en revistas especializadas y capítulos de libros sobre su tema de investigación. Además se desempeña como docente en la Universidad Nacional de la Patagonia San Juan Bosco.
} 


\section{Resumen:}

Los escritores argentinos Roberto Arlt y Raúl González Tuñón escribieron entre 1920 y 1930 un conjunto de textos que refieren a la costa del Río de la Plata. La propuesta de este artículo consiste en analizar de qué manera se vinculan los cambios urbanos y paisajísticos ocurridos en la zona con las representaciones configuradas por ambos escritores en sus producciones literarias. Se observará, en primer lugar, cómo fundan una nueva versión del espacio portuario a partir del armado de "escenas" en las que cruzan "la ciudad textual" con la "ciudad de cemento". En segundo lugar, se indagará cierta alternancia entre representaciones pintorescas del paisaje e imágenes que apelan a un tipo de mirada política y crítica sobre el desarrollo de este margen fluvial. Se analizará, entonces, de qué manera Arlt y Tuñón integran el espacio de la ribera a la nueva Buenos Aires modernizada, al mismo tiempo que revisan y cuestionan ciertas imágenes cristalizadas sobre el espacio.

Palabras clave: Río de la Plata; Modernización; Literatura Argentina; Arlt; Tuñón.

\section{Abstract:}

The Argentine writers Roberto Arlt and Raúl González Tuñón wrote a set of texts between 1920 and 1930 that refer to the coast of the Río de la Plata. The aim of this article is to analyze how the urban and landscape changes in the area are linked to the representations figured by both writers in their literary productions. Firstly, we observe how they found a new version of the portspace draw from the assembly of "scenes" in which they cross "the textual city" with the "city of cement". Secondly, we explore a certain alternation between picture representations of the landscape and images that appeal to a kind of political and critical view on the development of this fluvial margin. We will analyze, then, how Arlt and Tuñón integrate the riparian space into the new modernized Buenos Aires, at the same time that they review and question some crystallized images about the space.

Key Words: Río de La Plata; Modernization; Argentine literature; Arlt; Tuñón. 
"Las imágenes poéticas tienen también ellas, una materia".

Gastón Bachelard (2016: 10).

Indagar escrituras ligadas a cualquier tipo de metamorfosis urbana implica discurrir inevitablemente acerca de los modos en que lo material y lo imaginario se cruzan, se yuxtaponen y, también, discuten. Hipótesis como las de Peter Fritzsche sobre los cambios ocurridos en Berlín a comienzos del siglo $X X$, demuestran que una de las características fundamentales del proceso modernizador residió en el impacto que "la ciudad narrada" imprimió sobre "la ciudad de cemento" y viceversa(2008: 16).Como señala en su análisis, al mismo tiempo que escritores, periodistas y publicistas se inspiraron en los notorios cambios formales de la ciudad, los textos allí producidos "guiaron", "confundieron" y "modelaron la naturaleza de la experiencia metropolitana"(Fritzsche, 2008: 15). En el mismo sentido, si hacemos foco en los cambios ocurridos en Buenos Aires, encontramos que el enorme listado de textos surgidos entre las últimas décadas del siglo XIX y las primeras del XX no puede ser leído por fuera de los cambios reales experimentados en la urbe ya que, tal como señala Beatriz Sarlo, en ese contexto, "la literatura y la vida material se cruzaron en los registros más imaginativos de una nueva dimensión cultural" (1992: 17).

Dentro de los múltiples fenómenos de celebración y resquemor, de crecimiento y de inmovilidad que figuran bajo el amplísimo sintagma "proceso modernizador porteño" existen dos que, particularmente, afianzaron el protagonismo de Buenos Aires dentro del país antes del cambio de siglo: los nuevos tendidos ferroviarios y la construcción de modernas instalaciones portuarias. Si bien ambos acontecimientos fueron tematizados tanto por el periodismo como por la literatura y las artes en general, las modificaciones acaecidas en la costa del Riachuelo acapararon la atención de un sinnúmero de artistas y escritores que se ocuparon de retomar y renovar ciertos tópicos que redefinieron el paisaje de la ribera. Junto con el ecléctico grupo denominado "Pintores del Riachuelo" 2 y con loscronistas y escritores que representaron diferentes escenas portuarias (Félix Lima oManuel Gálvez, entre muchos otros), ${ }^{3}$ figuran también los "paisajes acuáticos"4 de Roberto Arlt y Raúl González Tuñón.

La propuesta de este artículo consiste, entonces, en indagar qué diálogos se establecen entre los textos que Arlt y Tuñón escribieron sobre la ribera y los cambios arquitectónicos y tecnológicosque allí se desarrollaron durante las décadas del '20 y del '30. Siguiendo a Bachelard en la cita que abre este trabajo, se intentará ligar la materia (las nuevas formas del puerto, el agua, las embarcaciones, los desarrollos tecnológicos) con las metáforas escriturarias propuestas por estos enigmáticos escritores argentinos para responder dos preguntas principales: ¿Qué recorridos por el Riachuelo configuran Arlt y Tuñón en sus escritos? ¿De qué manera se relaciona la alternancia entre imágenes "pintorescas" e imágenes "industriales" que figuran en estos textos con las transformaciones reales acontecidas en esos años en la zona?Con el afán de responder estas preguntas rectoras se intentará agregar a la historia cultural del paisaje del Riachuelo las voces de dos escritoresque, sin duda, asumieron la aventura de ser modernos. ${ }^{5}$

2. "Escuela del Riachuelo', o 'pintores de La Boca', la crítica ha elegido diversos nombres para nombrar un grupo plástico cuya producción es muy disímil-al punto que muchos críticos de arte se han negado a utilizar esta categoría-, reunidos por su relación con el sitio en que la mayor parte de su vida transcurre, por su ascendencia mayoritariamente italiana, y por sus orígenes humildes. El heterogéneo conjunto está constituido, habitualmente, por Lazzari, del Prete, Quinquela, Lacámera, Daneri, Cunsolo, Rosso, Tiglio, Menghi, Pacenza, Marezca, Stagnaro, Diomede, Mandelli; algunos agregan a Victorica (éste de orígenes nada humildes) y al grabador Arato" (Silvestri, 2012: 285)

3. En 1922 Manuel Gálvez publicó su novela titulada Historia de arrabal. Dentro de las incontables crónicas que circulaban en la prensa porteña de esos años sobre la zona del Riachuelo interesa señalar la columna que Félix Lima publicó alternadamente en Caras y Caretas alrededor de 1930 (algunos de los títulos son "Besos y lágrimas. Un motivito de la vida portuaria" o "De la concentración de nuestros buques de guerra en Puerto Nuevo").

4. Es una frase tomada de la crónica de Arlt titulada "La Paz de San Justo" (1932a: 6)

5. Tomamos el término "aventura" del reconocido libro de Marshall Berman: "Ser modernos es encontrarnos en un entorno que nos promete aventuras, poder, alegría [...] y que, al mismo 
Para ello, en un primer momento, se reseñarán brevemente los cambios ocurridos en la desembocadura del Río de la Plata entre finales del siglo XIX y principios del XX para, luego,observar qué vinculaciones figuran entre la geografía urbana y las descripciones escriturarias en los textos de Arlt y Tuñón. Por otro lado, en el segundo apartado, se estudiará cómo los escritores alternan en sus producciones entre un tipo de mirada pintoresca sobre el espacio y la configuración de panoramas políticos que tensionan ciertas imágenes ya cristalizadas sobre la ribera.

\section{Itinerarios}

En La grilla y el parque, Adrián Gorelik señala que la confianza en el progreso que se condensa con los festejos del Centenario de la Revolución de Mayo y el crecimiento desmedido de la ciudad desembocan en un desplazamiento de la actividad política y cultural hacia los márgenes:

En muy poco tiempo, entre los últimos años diez y los primeros veinte, el suburbio avanza sobre el centro ocupando rápidamente las principales atenciones políticas, culturales y urbanísticas; ya no las abandonará, hasta que quede claro que el crecimiento urbano no había sido un fenómeno independiente de las cualidades de la ciudad tradicional, sino que las había afectado al punto de disolver su propio sentido, replanteando las bases mismas sobre las que hasta entonces se había considerado el espacio público. Así, en los años veinte y treinta, será el pensamiento sobre el suburbio donde se jueguen las posiciones ideológicas acerca de la definición de Buenos Aires y su futuro (2016: 309-310).

tiempo, amenaza con destruir todo lo que tenemos, todo lo que sabemos, todo lo que somos" (1992: 1).
Si bien el puerto es uno de los espacios que entra en tensión cuando se redefine la ciudad, las producciones sobre los márgenes fluviales porteños no problematizan los mismos tópicos que los textos y las imágenes que tematizaron el ingreso de la pampa a la cuadrícula urbanaestamos pensando en algunos cuadros de Pío Collivadino, ciertas fotos de Horacio Cóppola, el Don Segundo Sombra de Güiraldes, la primera poesía deBorges o parte de las mismas aguafuertes porteñas deArlt, entre muchísimos otros ejemplos-. ${ }^{6}$ En el puerto no aparecen ni el gaucho, ni los animales, ni el horizonte abierto, ni el pajonal, sino, en cambio, un mundo cruzado por la inmigración, el conventillo, el colorido, la pobreza, la industria, las embarcaciones y el río como puerta hacia lo desconocido. Ese espacio al que, casi cuatro siglos antes, había llegado Pedro de Mendoza, proponía en las primeras décadas del XX otras imágenes en torno al crecimiento urbano.

Si bien el aspecto de este puerto se había mantenido casi idéntico desde la fundación de la ciudad, fue hacia finales del XIX cuando se desencadenaronuna serie de transformaciones arquitectónicas que modificaron su forma. Tal como señala Silvestri, son las mismas embarcaciones las que demandan cambios en la infraestructura portuaria:
...el nuevo problema que debían enfrentar los puertos del siglo XIX consistía en el aumento constante del tamaño de los barcos: se tra- taba, en suma, de un problema de flexibilidad de la construcción. El programa portuario se enfrenta

\footnotetext{
6. Sobre este tema puede mencionarse el libro de Graciela Montaldo en el que observa: "...la modernidad incipiente pero irreversible de la literatura argentina del Fin de Siglo, aun cuando se impregne de las modalidades culturales de la vida urbana (de Buenos Aires y de las versiones que llegan de las ciudades europeas a través de los barcos, las revistas, las fotografías, los viajes), tiene aún un pie en la tradición rural que no terminará de sacar a lo largo del siglo XX. Y, lo más singular, por propia voluntad. La referencia a lo rural será menos un contenido que una tensión constante hacia ese pasado cultural del que parecen provenir tantos sentidos y desde entonces la vida cosmopolita constituye literariamente lo rural. La ciudad y el campo - sus prácticas y sentidos - son dos especies que en la cultura argentina, desde el Fin de Siglo, no dejan de formar un complejo que ya no hay modo de pensar por separado" (1993: 19).
} 
así con uno de los problemas que signan las instalaciones productivas del siglo XIX: un ritmo de crecimiento que pareciera no agotarse jamás. Un diagrama presentado en 1908 por G. Hersent demostraba el continuo crecimiento de los buques de ultramar desde 1830 hasta la fecha y su proyección hacia 1920: de 50 metros de largo, los buques habían pasado a casi 250 metros con el Lusitania. Y los buques se construían mucho más rápido que un puerto (1993: 105).

Por eso, en1875 comienza a dragarse el Riachuelo para convertirlo en puerto de cabotaje. En este marco surge la reconocida disputa Huergo-Madero que finaliza en 1886 con el inicio de las reformas a cargo del segundo. ${ }^{7}$ El vicepresidente Pellegrini condujo en 1889 la inauguración de la sección sur y le confirió el nombre de "Puerto Madero". Como observanal respecto Scobie y De Lazzi, "La crisis financiera de1890-91 demoró la construcción y aumentó los costos, pero de todos modos el trabajo continuó: los diques primero y segundo (numerados de sur a norte) se completaron en 1891; el tercero, en 1892; el cuarto, junto con la dársena norte del puerto, en 1897, y el sistema completo fue abierto al comercio en 1898 con el dragado final del canal norte"(1992: 22). Si bien la obra facilitó el intercambio de las exportaciones agrícolas por manufacturas importadas, "las instalaciones se manifestaron inadecuadas para las necesidades del país y errores técnicos en el cálculo complicaron el problema. Los barcos no podían amarrar con seguridad [...] mientras que las dificultades en la construcción de los accesos ferroviarios forzaron la continuada dependencia en el sistema de lanchas, carros y peones" (1992: 23).De forma tal que, en 1907, se aprobó un proyecto para realizar algunas mejoras en el puerto que finalizaron en 1911. Mientras tanto, en 1909 el Ministerio de Obras Públicas "propuso al Presidente construir el Puerto Nuevo partiendo del extremo norte del canal principal de acceso al costado de los terrenos ganados al río por el Ferrocarril Pacífico

7. Sobre esta disputa véase Silvestri (2012) y defendido por un malecón exterior" (1992: 23). Se llamó a un concurso, y en 1911 se aprobó el proyecto de C.H Walker y Cía. La obra fue interrumpida por la crisis en torno a la Primera Guerra Mundial y se extendió mucho más de lo esperado: "En agosto de 1932 el puerto seguía sin terminarse y el presidente Justo decidió poner fin a la situación enviando al Congreso un proyecto de ley que contemplaba algunas instalaciones consideradas indispensables: construcción de una estación marítima para pasajeros y la prolongación y construcción de varios conductos para aguas pluviales"(1992: 24).En este marcoemergen en la escena literaria un conjunto de textos firmados por figuras destacadas del ámbito cultural porteño queincluyen la zona del Riachuelo al mapa de las representaciones artísticas de la nueva Buenos Aires; se trata del primer poemario de Raúl González Tuñón, El violín del diablo(1926), ${ }^{8}$ yde unapequeña y discontinua serie de aguafuertes porteñas de Roberto Arlt impresas en el diario El Mundoentre 1929 y $1933 .{ }^{9}$

Cruzados por el trabajo y por la amistad, ambos escritores comienzan a ser visibilizados a mediados de la década del '20 a partir de producciones difíciles de encasillar. ${ }^{10}$ Como refiere

8. Si bien el puerto reaparecerá en la obra de Tuñón, nos centraremos únicamente en este primer libro ya que los poemas que lo constituyen refieren mayormente al puerto porteño. Además, tal como señala María Fernanda Allé, en los inicios de la década del treinta el poeta comienza a delinear en sus textos lo que la investigadora define como "poética de la convocatoria": "una poética que, desde el ejercicio de una práctica literaria confiada en su capacidad para intervenir en la transformación del mundo, tiene por fin exhortar a la lucha, sumar voluntades a las causas partidarias y ponderar las acciones del partido frente a cada enemigo ocasional" (2017: 13). Así, la alternancia entre paisaje pintoresco y paisaje político que aquí trabajaremos, desaparece.

9. En 1926 Arlt publicó El juguete rabioso, y en los años que escribe las notas que estudiaremos también publicaLos siete locos (1929), Los lanzallamas (1931) y El amor brujo (1932), entre otros textos narrativos. Además, si bien no forma parte de nuestro análisis, no puede dejar de mencionarse que en 1937 Arlt estrenó una obra teatral en la que aparece el puerto como válvula de escape de la alienante rutina urbana,La isla desierta.Allí, los protagonistas se revolucionan cuando el jefe los muda del subsuelo a un espacio desde el cual puede verse y oírse el puerto. El contacto que establecen con los barcos que entran y salen, sumado al discurso de Cipriano (un mulato que ha recorrido el mundo) los lleva a problematizar las condiciones en las que trabajan y a plantearse la posibilidad de abandonar todo para viajar.

10. Esto puede visualizarse con claridad si se analiza qué luga- 
Saítta, lo novedoso e inclasificable de los textos arltianosresidió, en un comienzo, en su manifiesta intención de elevar "el idioma de la calle, la lengua plebeya, a idioma nacional consolidando simultáneamente un lugar de enunciación dentro de las páginas de un diario y un lugar de enunciación, una entonación, dentro de la literatura argentina"(2008: 81). Pero, además, continúa la investigadora siguiendo a Sarlo, ${ }^{11}$ "Arlt combina el uso de las voces de la calle con la exhibición constante de un saber literario, al que se suma la apropiación de discursos ajenos a la literatura, esos 'saberes del pobre' que incorporan el léxico de la química, la física, la geometría, las ciencias ocultas, el magnetismo, la teosofía, para representar una subjetividad, un paisaje, una acción"(Saítta, 2008: 81-82). Con respecto a los inicios de Tuñón, interesa destacar que, si bien este primer poemario podría ser leído "como una actualización y traducción de toda la imaginería baudeleriana de barcos, marineros, prostitutas y fumaderos" (Prieto, 2006:

res ocuparon ambos escritores en la polémica Boedo/Florida ya que, más allá de que fueron "los mismos actores del enfrentamiento [quienes] desmintieron su existencia, o la circunscribieron a una beligerancia juvenil sin consecuencias textuales específicas..." (Prieto, 2006: 223), Martín Prieto también señala que autores como Raúl González Tuñón, Roberto Mariani o Nicolás Olivari, neutralizaron los términos de la oposición al "responder simultáneamente a las consignas floridistas y boedistas" (2006:223). En consonancia con esto, Claudia Gilman señala sobre el lugar de Arlt dentro de la disputa: "El diálogo de sordos ha sido definido por los propios polemistas. De la polémica Florida-Boedo ya se ha dicho, que ha sido en serio y ha sido en broma. Tal vez pueda sostenerse la verdad de ambas afirmaciones. Hay dos programas, dos estéticas, dos empresas culturales y dos públicos que se complementan más de lo que se superponen. Como neutral privilegiado, que encarna simbólicamente a ese testigo al que se busca convencer, queda Roberto Arlt para ocupar el lugar de la manzana de la discordia: como un eco residual de la polémica se desarrolla una lucha por considerar a Arlt como uno de los 'nuestros'. La disputa, vaciada de sus contenidos estético-ideológicos, sedimenta en la propiedad de un Arlt-trofeo" (2006: 54).

11. Refiere Sarlo en Una modernidad periférica: "En verdad, las ficciones arltianas podrían ser leídas desde la perspectiva de alguien que no posee saberes prestigiosos (los de las lenguas extranjeras, de la literatura en sus versiones originales, de la cultura tradicional y letrada) y que recurre a los saberes callejeros: la literatura en ediciones baratas y traducciones pirateadas, la técnica aprendida en manuales o revistas de divulgación, los catálogos de aparatos y máquinas, las universidades populares, los centros de ocultismo. Prácticas y discursos en busca de una legitimación que, más que competir con los consagraos, crean su propio circuito: allí están los inventores populares (de los que había cientos en el período), como Silvio Astier o Erdosain, como el mismo Arlt, que persigue hasta su muerte el descubrimiento que haga posible la rosa metalizada" (1988: 55-56).
236), en estos textos inaugurales el poeta no copia, sino que cruza esas imágenes portuarias ajenas con su experiencia personal, con la "fantasía" y con la "imaginación", dando forma a lo que Prieto denominó "realismo impuro" o "romántico" (2006: 236-237).

Ahora bien, cuando intentamos reconstruir cuál es la geografía que configuran estos textos, rápidamente notamos que, a pesar de que en las crónicas de Arlt las alusiones cartográficas resultan más abundantes que las que figuran en los poemas de Tuñón, ${ }^{12}$ la representación espacial del Riachuelo que arman estos textos se asemeja más a un patchwork que a un mapa. Ambos escritores aglutinan en sus producciones referencias a puntos estratégicos o nombres propios ("Barracas", "La Boca", "Pedro de Mendoza", "Dock Sud”, etc.) que, al modo de indicadores espaciales, ubican a los lectores en los escenarios en los que suceden las anécdotas referidas y, en ese cruce entre "lo real" y "lo imaginario", consolidan otras versiones del Riachuelo porteño.Así, por momentos, el puerto se tiñe de negro al modo de los grabados de los Artistas del Pueblo: "Dock Sur durante el día es sombrío como una aguafuerte de Facio" (1931a: 6), señala Arlt; "Calle Pedro de Mendoza, Bodegones sombríos, /Gente que viene de lejanos mares / y de lejanos ríos /y la oficina en los altares /del alcoholismo y de los desvaríos", refiere Tuñón en su poema titulado, precisamente, "Aguafuerte" (1972: 33). ${ }^{13}$ En otros casos la zona es representada no por el sentido de la vista, sino por la incorporación de sonidos cosmopolitas: "Música de los puertos siempre igual /y distinta. /Políglota. Tus velas /se izaron a los vientos más extraños" (Tuñón, 1971: 51). Y si bien esto ha sido mencionado numerosas

12. Esta diferencia se debe a que se trata de dos géneros diferentes: poesía y crónica periodística. En efecto, tal como señala Ramos, la puja entre narración e información es inherente a la crónica latinoamericana desde finales del XIX: "Para poder hablar en el periódico, el literato se ajusta a la exigencia del mismo: informa, e incluso asume la información como un objetivo privilegiado de su reflexión. Pero al 'informar' sobre-escribe: escribe sobre el periódico que continuamente lee, en un acto de palimpsesto, digamos, que a la vez proyecta un trabajo verbal sumamente enfático, que la noticia - el objeto leído- no tenía" (1989: 110-111).

13. Sobre los vínculos entre la poética de Arlt y los Artistas del Pueblo puede consultarse el estudio de Eleonora Frenkel (2015). 
veces por la crítica de Tuñón,y es un dato que aparece ya en el mismo título del poemario El violín del diablo-,resulta sugerente encontrar correspondencias en las descripciones arltianas: "No sé de dónde viene una canción en voz baja.......] Es la hora en que los capitanes y segundos comandantes reciben una visita a bordo y destapan una botella de ron de Jamaica, diciendo con tono pensativo: 'The sea will be rough tonight'..." (1933e: 15).

El puerto puede ser, entonces, una aguafuerte, o una canción desconocida, pero también,tal como lo indica el nombre que Tuñón le da a uno de sus poemas, es el "bajo fondo" porteño, escenario del crimen y de la marginalidad. A modo de ejemplo pueden mencionarse el poema "Puente Alsina" y la nota homónima de Arlt impresa en El Mundo en 1932. Ya que, a pesar del deseo explícito del aguafuertista por separarse de lo ya dicho por Tuñón - "Tampoco quisiera hacer un elogio del Riachuelo, puesto que ya lo hicieron Enrique y Raúl González Tuñón y su condigno cofrade, [...] Carlos de la Púa, con frases resonantes que parecen chicotazos. De modo que me atenderé a lo bucólico. Y a lo que he visto; que ya es algo" (1932b: 6) —, y de las menciones concretas sobre el barrio en el que se inserta el puente (que no figuran en el poema) - "A tres cuadras de Puente Alsina, bruscamente, como la celada que se manifiesta en un momento de asalto, la calle se estrecha indefinidamente, encajándose entre una hilera de ignominiosos 'bungalows' de lata y madera pintada de verde... (1932b: 6)"-tanto en el poema como en la nota aparece esta tercera modulacióndel puerto como escenario del crimen: "Puente Alsina: /Te corta el riachuelo-como un barbijo. /Alimento de crónicas policiales [...] / Los ladrones y los poetas no te tenemos miedo" (1972: 86), refiere el Tuñón; mientras que Arlt, en un tono más periodístico, observa sobre los alrededores del puente: "La calle Sáenz tiene la anchura correspondiente a las necesidades de un raje en diez direcciones distintas, después de un golpe a mano armada. Nuestros pistoleros la utilizan siempre, y no hay maleante que no se la conozca de punta a rabo" (1932b: 6).

Entonces, si como señala Michel De Certeau, "[La descripción] Es, pues, fundadora de espa- cios" (2000: 136),podemos afirmar que el puerto que fundan estos escritores en sus obras surge de lo material, de esa costa en permanente mutación formal y cultural, pero no intenta reflejarlo. Por el contrario, Arlt y Tuñón describen el Riachuelo, y en el ejercicio escriturario, lo inventan; juegan con lo que encuentran o con lo que imaginan y le agregan a lo ya dicho y pintado por otros artistas nuevos matices: en los poemas de El violín del diablo aparece el circo, el opio, la prostitución y el tango; en las crónicas de Arlt los barcos, las grúas y los remolcadores se transforman, por momentos, en monstruos novelescos.Como pudo verse en las diferentes citas, en estos textos no se configuran itinerarios "reales", sino diferentes escenas ficcionales ancladas en la geografía fluvial porteña que, al ser leídas en conjunto, proponen un tipo de recorrido que combina lo experiencial (lo visto y lo oído), con lo arquitectónico y lo ficcional, aportando así otra mirada sobre el espacio a la historia de la ribera porteña.

\section{Entre el paisaje pintoresco y el paisaje político}

Como vimos, entonces, los textos de Arlt y Tuñón no proponen trayectos concretos en sus descripciones, lo que hacen, en cambio, es articular indicadores espaciales reales con lo que ellos leyeron, vieron o escucharon sobre este río. Lo que les interesa, sin dudas, es definir otra imagen de la costa porteña e integrar el espacio al centro urbano que, en esa época, se reducía casi exclusivamente a la calle Corrientes: ${ }^{14}$ "Muelle de pescadores. Frente de la gran urbe. /Allí transpira la ciudad reseca" (Tuñón, 1972: 48). No existe en sus producciones un afán por documentar con exactitud las dimensiones o la forma del espacio, sino un intento por visibilizar y apropiarse del margen más cosmopolita de

14. "Caída entre los grandes edificios cúbicos, con panoramas de pollos a 'lo spiedo' y salas doradas, y puestos de cocaína, y vestíbulos de teatros iqué maravillosamente atorranta es por la noche la calle Corrientes! ¡Qué linda y vaga! Más que calle parece una cosa viva, una creación que rezuma cordialidad por todos sus poros [...] Corrientes, la calle vagabunda, enciende a las siete de la tarde todos sus letreros luminosos y, enguirnaldada de rectángulos verdes, rojos y azules, lanza a las murallas blancas sus reflejos de azul de metileno, sus amarillos de ácido pícrico, como el glorioso desafío de un pirotécnico" (Arlt, 1929a: 4) 
Buenos Aires. Frente a esto, nos interesa indagar ahora las diferentes temporalidadesy estéticas que figuran en los paisajes configurados en sus escritos. Porque si el modo en que integran las referencias geográficas señala un anclaje parcial en el espacio, la alternancia entre imágenes pintorescas y panoramas políticos que aparece en estos textos deja en evidencia cierta dificultad a la hora de representar la zona en tiempo presente y señala una vez más, el cruce entre la mirada literaria y las transformaciones materiales atravesadas por el puerto porteño.

Graciela Silvestri y Fernando Aliata señalan que en la mirada paisajística figuran implícitos el viaje y el arte:

Para que exista un paisaje no basta que exista "naturaleza", es necesario también un punto de vista y un espectador; es necesario también un relato que de sentido a lo que se mira y experimenta, es consustancial al paisaje, por lo tanto, la separación entre el hombre y la naturaleza. No se trata de una separación total, sin embargo, sino de una ambigua forma de relación, en donde lo que se mira se reconstruye a partir de recuerdos, pérdidas, nostalgias propias y ajenas, que remiten a veces a larguísimos períodos de la sensibilidad humana, otras a modas efímeras. La mirada paisajística es la del exiliado, del que conoce su extrañeza radical con las cosas pero recuerda, o más bien construye, un pasado, una memoria, un sentido (2001: 10).

En vinculación con esto, podemos observar que Arlt y Tuñón no miran el espacio ribereño siempre desde el mismo punto de vista, sino que se mueven, transforman sus miradas y cambian sus perspectivas. Frente al río pintoresco vemos aparecer un río industrial, tecnológico, que define otro paisaje, el político. ${ }^{15}$

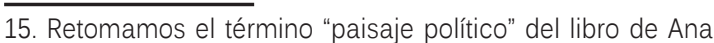

La costa del Riachuelo es, se supone, el espacio donde se originó Buenos Aires; sin embargo, no resultó siempre atractiva para los extranjeros que llegaban a nuestras tierras. Ciertamente, tal como señala Silvestri, cuando algún viajero de principios del siglo XIX "realiza una mención vinculada con el Riachuelo [...] la descripción carece de acentos paisajísticos" (2012: 61).Fue el ingeniero y pintor Carlos E. Pellegrini en las primeras décadas del 1800 quien le aportó un matiz pintoresco a la orilla. En sus obras es donde aparece por primera vez el río "como tema específico de la estampa, sin asunto narrado que coloque al paisaje sólo como fondo" (Silvestri, 2012: 62). En sus vistas, Pellegrini "coloca dentro de una sintaxis preestablecida objetos del repertorio local. No intenta salir de un esquema previo, aunque este mismo esquema revela por contraste las diferencias entre este paisaje poco caracterizado y los trabajados paisajes del viejo mundo" (2012: 64). Estos panoramas naturales en los que aparecen las primeras construcciones de la zona, personajes aislados y barcos a vela deslizándose por un río calmo son los que,de alguna manera, figuran (aunque reversionados) en los textos de Arlt y Tuñón:

Hay que ir al puerto, aunque más no sea para darse un baño de luz de viajes. [...] En el puerto se respira. En el puerto se bebe paisaje. En el puerto se recobran los sueños de la niñez. En el puerto se purifica el alma. En el puerto se aprende a soñar. A esperar, como esperan los transatlánticos. Una mañana perdularia por los diques produce sobre la imaginación los mismos efectos que una inyección de vitaminas. El vigor de la luz levanta la tapa de los cielos que aparecen más altos y perfectos. El espacio se comba alegremente sobre la arboladura de los mástiles de acero y enrededor de las finas telarañas de las antenas de radio (Arlt, 1933b: 9). Yo que vi algunos puertos

Porrúa (2011: 117). 
los unos aquí fantásticos, inciertos. Porque todos los puertos se parecen. —Grúas, máquinas, barcos

y almas que a los vientos se estremecen

y que manchan sus velas en los charcos.

Calle Pedro de Mendoza. Bodegones sombríos.

El niño buscador, triste, fogoso, saldrá tal vez mañana en un navío rumbo a un país lejano y misterioso abandonando el patio luminoso de la ciudad, sonoro y encendido (Tuñón, 1972: 34).

Arlt y Tuñón configuran, así, por momentos, un puerto protagonizado por velas agitadas en el que la luz y el aire revitalizan al paseante —vagabundo o flâneur-que contempla el espacio como una válvula de escape de la monstruosidad urbana. Como Quinquela Martín, el gran pintor de La Boca, que "introduce [en sus cuadros] otra duración en la temporalidad urbana: la duración de lo natural, aquello de lo que la ciudad proviene y hacia lo que va" (Silvestri, 2012: 318),estos escritores se detienen a contemplar el puerto y sus embarcaciones: "Ved la barca costera junto a la escalerilla, I después de un día intenso de pesada labor. / Al verla, dan deseos de sentarse a la orilla, /y limpiarle el sudor!" (1972: 46), señala Tuñón en su poema "La barca costera", mientras que Arlt refiere en una nota posterior cuyo título es casi idéntico: "El día en que Ud. esté agriado, aburrido, vaya al puerto; pero no a hombrear bolsas... Siéntese a la orilla de un murallón; apoye la esquena en el caballete de una grúa y quédese una hora con la mirada perdida en ese bosque de mástiles entrecruzados en todos sus ángulos por cables y sogas..." (1931b: 31). Incluso, en algunos casos aislados, esta preponderancia del colorido portuario se complementa con una visión desproblematizada del trabajo: "iAh, estos trabajos marítimos”! Livianos y semejantes al juego" refiere el cronista en "Matices portuarios" (1933b: 9), y Tuñón, por su parte, los describe en medio de una fiesta circense: "Estampas, luces, musiquillas. /Misterios de los reservados /donde entrarán casi a hurtadillas /los marinos alucinados" (1972:
66). Si bien esta mirada no es la única, el fuerte hincapié en el colorido del espacio que allí figuralos desplaza hacia atrás en la línea del tiempo.

Coincidentemente, cuando Silvestri analiza las representaciones visuales (pictóricas y fotográficas) sobre el Riachuelo señala que "En las fotografías de la década de 1880, las altas arboladuras de los barcos indican aún la presencia de velas; ellas dejan de definir el lugar hacia 1920, aunque persisten en las representaciones" (2012: 219).En este sentido, observamos que aún hacia finales de los años '20 y entrada la década del '30, Arlt y Tuñón incluyen en algunos de sus textos un puerto pasado. Persiste en ambos autores el deseo por preservar la imagen del Riachuelo como puerta hacia el mundo, como zona cosmopolita, viajera y amena que invita a la aventura:

Pasa una canción triste. En ese barquichuelo cansado y achacoso de tanto navegar,

hay alguien que nostálgicamente contempla el cielo.

¿Qué pesa en la tristeza de este lobo de mar?

Dadle un barco a ese viejo; dadle dos tripulantes

Y que zarpe mañana con las velas al viento... (Tuñón, 1972:47). ${ }^{16}$

No obstante, en otros de los textos que integran este corpus, ingresan las novedades tecnológicas, arquitectónicas, sociales e industriales que conforman lo que más arriba definimos como "paisaje político". Y aquí nuevamente nos enfrentamos al fenómeno que Gorelik encuentra en las obras posteriores de Daniel García Helder y Félix Rodríguez: "el arte y la ciudad se potencian mutuamente" (2013: 14).Porque si en los años en los que Arlt y Tuñón escriben sus textos convivían en aquel

16. Es interesante el caso de este poema, "Lobos de mar", porque la clara influencia de Rubén Darío que figura en sus versos demuestra que el vaivén temporal que encontramos en las imágenes también aparece en la inclusión de procedimientos y temas provenientes de estéticas anteriores que aún resonaban en los imaginarios literarios ligados a la vanguardia. 
puerto a medio terminar el colorido de ciertas estampas pintorescas anteriores con el notorio crecimiento industrial, la proliferación de conventillos superpoblados y la inclusión de nuevas maquinarias, encontramos que ese diálogo entre representaciones espaciales "residuales" y "emergentes" impacta en las imágenes escriturarias que aparecen tanto en las crónicas como en los poemas:

Por donde se vaya, no se ve nada más que el triunfo de la máquina y del fuego: fundiciones de hierro y de cristal; fábricas de jabón, de ácido nítrico y de bulones. Las sierras metálicas chirrían continuamente; grandes guinches mueven masas metálicas rojizas; un sauce, una curva de agua, un bote... Y luego el panorama enorme con las tres chimeneas escalonadas de una fábrica que lanzan al cielo torbellinos de humo en esfuerzo de maquinarias invisibles, pero ciclópeas. Más allá la visión de los mástiles de Buenos Aires...(Arlt, 1929b: 4)

Pasan los hombres negros descargando carbón,

y se incendia la tarde en los rayos crueles,

en los rayos desnudos de un magnífico sol.

¡Trabajadores negros, y fuertes y ceñudos

que componéis el noble poema del sudor!

[...]

Sobre la piedra ardiente del puerto, indiferentes,

pasan los hombres negros descargando carbón.

¡Ah si todos tuvieran un hogar! Si la sopa

dijera para todos su sentida canción!

La tarde que revienta, está pariendo el sol (Tuñón, 1972: 50).
Así como dentro de un mismo poemario Tuñón incluye "Lobo de mar" y "Descarga de carbón", textos en los que las visiones sobre el puerto convocan imaginarios disímiles, Arlt, por su parte, imprime el día 28 de julio de 1933 "Matices portuarios" (nota en la que se destacan frases como: "en el puerto se bebe paisaje") y, al día siguiente, "Cargando carbón en el puerto", una crónicaen la que desarrolla el mismo tópico industrial que figura en el poema de Tuñón citado más arriba:

El vapor del agua, escape de las calderas de las grúas, de las locomotoras pequeñas y antiguas con adornos de bronce, el vapor de las naves y de las lanchas aclara por momentos el aire con una niebla blanca, pero luego se impone y triunfa nuevamente el polvillo de hulla y en esta atmósfera enrarecida, de usina al aire libre, los brazos de los guinches se entrecruzan y mueven como mandíbulas de hormigas gigantescas, atareadas en un trabajo descomunal y urgente (1933c: 7).

El paisaje se politiza, entonces, en dos sentidos. Por un lado, surge el deseo de testimoniar el proceso de modernización e industrialización porteña que también figura en pinturas reconocidas de Quinquela Martín como "Descarga de carbón con grampas" de 1928 (Figura 1) ${ }^{17}$, o en algunos cuadros de Alfredo Guttero como "Molino El Porteño" (1928),en el que las chimeneas,

17. Diana Wechsler refiere acerca del vínculo entre paisaje pintoresco y trabajo en Quinquela Martín: "El puerto de La Boca y sus alrededores, la zona de Puerto Madero, la ribera y Barracas son los rincones elegidos por quienes eligen una mirada pintoresca. Se tipifican estas regiones de la ciudad y sus pobladores neutralizando toda perspectiva crítica por medio de un partido estético descomprometido [...] Pero no todas las versiones son iguales. Planteos como los de Eugenio Daneri o Benito Quinquela Martin revelan un tratamiento más humanizado de los mismos temas. La gestualidad impresa en las obras -el uso de la materia densa y vibrante- denota un acercamiento sensible al mundo del trabajo, muestra interés no sólo por los barcos y sus reflejos en el agua, o por las vistas panorámicas del puerto, sino que también se detiene en los hombres que lo transitan y sufren. Aquí el pintoresquismo se humaniza, sin llegar a convertirse en una imagen crítica: tales trabajos están comprometidos con lo vivencial" (2010: 281-282). 
Figura 1: Quinquela Martín, Benito.

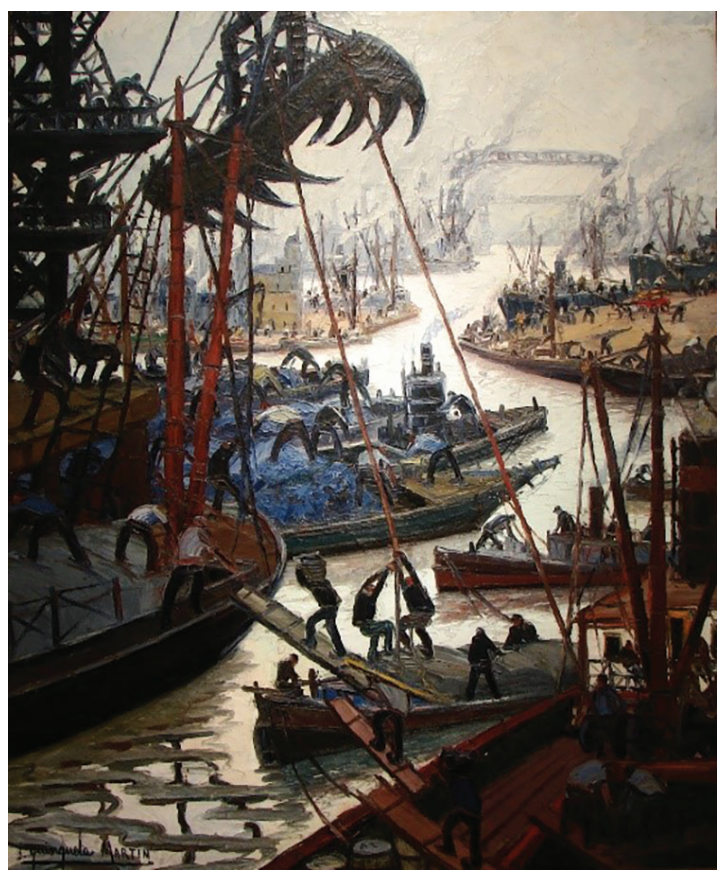

Fuente: Descarga de carbón con grampas, 1928.

y la atmósfera fabril se imponen sobre el resto de los elementos que componen la estampa (Figura 2).$^{18}$ Pero, además,en estos textos aparece también una fuerte crítica a la hostilidad de la vida y del trabajo de los habitantes del puerto:"Colilla de cigarro. /Baba de marineros borrachos /y mujeres curtidas /por los vientos del mar y del trabajo" (Tuñón, 1972: 72). Esta mirada social que en Tuñón irá profundizándose con el correr de los años, y que en Arlt figura en toda su obra narrativa y periodística desde $E /$ juguete rabioso ${ }^{19}$, pone en tensión las representaciones pintorescas analizadas más arriba: “... frente a un dique flotante, se encuentra una chata de hierro no terminada. Hace un año que está allí ante el agua que la reclama, y el óxido avanza lentamente su lepra roja en los flancos

18. "Cuando Guttero regresa al país, registra el cambio de la ciudad y se demora en la observación del Puerto Nuevo, de los silos y las grúas de las dársenas. No es una observación superficial, sino la de quien traduce lo real en la armonía de los geométrico" (Orgambide, 2000: 6).

19. No sólo impera en su modo de ver el mundo, sino que además dentro del gran conjunto de crónicas que imprime entre 1928 y 1942 en El Mundo figuran pequeñas series dedicadas a la denuncia de problemas vinculados con el crecimiento urbano como, por ejemplo, "Hospitales a la miseria" (1933) o "Buenos Aires se queja" (1934)
Figura 2: Alfredo Guttero

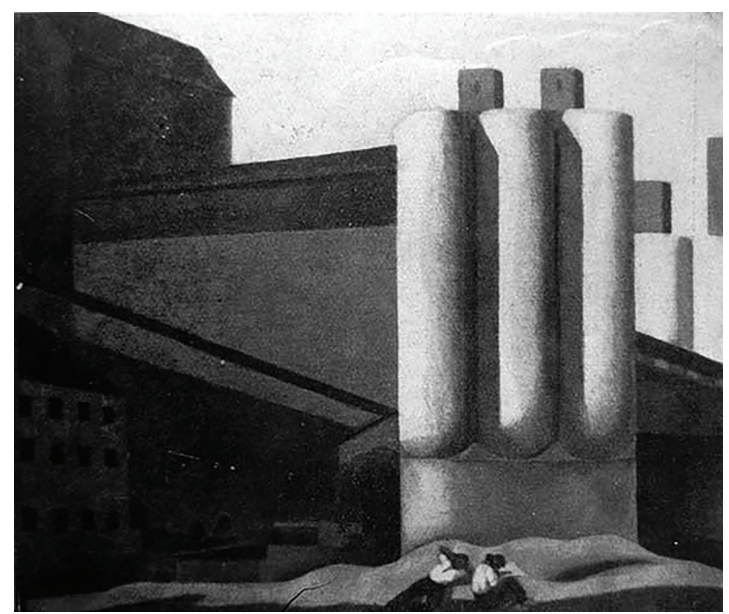

Fuente: Molino El Porteño, 1928.

curvos y la barcaza parece pregonar su esterilidad, de la cual son culpables los hombres vestidos de azul" (Arlt, 1933d: 6).

La mirada de estos autores se politiza no sóloporque denuncian o representan conflictos sociales, sino porque, tal como señala Jacques Rancière, "forjan contra el consenso otras formas de 'sentido común', formas de un sentido común polémico" (2010: 77). ${ }^{20}$ Desde el interior mismo de las obras, los textos de Arlt y Tuñón articulan el paisaje pintoresco ya afianzado en el imaginario cultural de la época con las nuevas imágenes urbanas que la ciudad material proponía a sus artistas y, también, por momentos lo cuestionan. En la búsqueda por trastocar una imagen ya cristalizada sobre la zona del Riachuelo (una imagen colorida que, en parte, pervive hasta la actualidad), estos escritores incorporan a sus "paisajes acuáticos" las novedades tecnológicas, sociales y urbanísticas de

20. No sólo impera en su modo de ver el mundo, sino que además dentro del gran conjunto de crónicas que imprime entre 1928 y 1942 en El Mundo figuran pequeñas series dedicadas a la denuncia de problemas vinculados con el crecimiento urbano como, por ejemplo, "Hospitales a la miseria" (1933) o "Buenos Aires se queja" (1934). 
un puerto que, desde fines del siglo XIX, se encontraba en permanente mutación.

\section{Conclusiones}

Cómo convive la "ciudad textual" con la "ciudad de cemento" en la zona de la ribera porteña durante las primeras décadas del siglo XX, fue el interrogante que intentamos desandar a lo largo de este artículo. Leer el primer poemario de Tuñón y la pequeña serie de crónicas arltianas teniendo en cuenta los cambios reales acontecidos durante esos años en el Riachuelo nos permitió conectar lo material con lo imaginario. Así, vimos cómo ambos escritores fundan una versión propia del puerto a partir de descripciones que incluyen referencias reales, pero también metáforas, giros lingüísticos e imágenes pasadas.

Si la historia del espacio señala el pasaje del siglo XIX al XX como una época de grandes cambios (construcción del Puerto Madero, inicio de la obra del Puerto Nuevo, etc.), esa alternancia entre lo que la costa había sido desde la fundación de Buenos Aires y la imagen de una zona en plena modernización, se evidencia también en el cruce entre paisaje pintoresco y paisaje político que estudiamos en los textos. El puerto es, sin dudas, para Arlt y Tuñón el margen cosmopolita, la frontera que conecta a Buenos Aires con el mundo, pero también el bajo fondo donde marineros, obreros y prostitutas trabajan sin descanso, donde los inmigrantes viven hacinados en conventillos y donde, junto al río oleoso, "los elevadores de granos parecen fantasmas cubistas entre la neblina" (Arlt, 1933e: 15). Condicionados por la forma de "lo real", estos escritores describen la ribera porteña y, de ese modo, agregan ese espacio marginal a la Buenos Aires literaria, al mismo tiempo que suman una nueva versión del puerto a la historia del paisaje cultural del Riachuelo en la que conviven las barcas de Baudelaire, los marineros de Rubén Darío, las aguafuertes de Facio Hebequer, los colores de Quinquela, las fábricas de Guttero, las experiencias de tránsito de cada autor y el interés por visibilizar la vida pesarosa de quienes no figuran en las postales.

\section{Bibliografía}

Allé, M.F. (2017). El tránsito hacia la revolución. Raúl González Tuñón en la primera mitad de los años treinta". El taco en la brea (Santa Fe), 5, 10-38. Recuperado de: http://bibliotecavirtual.unl.edu.ar/ojs/index.php/ElTacoenlaBrea/article/view/6613. DOI: https://doi.org/10.14409/tb.v1i5.6613

Arlt, R. (26 de marzo de 1929a). Corrientes por la noche. El Mundo, p. 4.

Arlt, R. (8 de mayo de 1929b). El remolino. El Mundo, p. 4.

Arlt. R. (30 de marzo de 1931a). Acordeón en Dock Sur. El Mundo, p.6.

Arlt, R. (14 de abril de 1931b). Barcas en el Riachuelo. El Mundo, p. 21.

Arlt, R. (27 de febrero de 1932a). La paz de San Justo, El Mundo, p. 6.

Arlt, R. (2 de marzo de 1932b). Puente Alsina. El Mundo, p. 6.

Arlt, R. (5 de junio de 1933a). 20 grúas abandonadas en la Isla Maciel. El Mundo, p. 10.

Arlt, R. (28 de julio de 1933b). Matices portuarios. El Mundo, p. 9.

Arlt, R. (29 de julio de 1933c). Cargando carbón en el puerto. El Mundo, p.7.

Arlt, R. (30 de julio de 1933d). El cementerio de las naves". El Mundo, p. 6.

Arlt, R. (31 de julio de 1933e). Anochecer lluvioso en el puerto. El Mundo, p. 15.

Bachelard, G. (2016). El agua y los sueños: ensayo sobre la imaginación de la materia. México: Fondo de Cultura Económica.

Berman, M. (1992).Todo lo sólido se desvanece en el aire. La experiencia de la modernidad. Buenos Aires: Siglo Veintiuno Editores. 
De Certeau, M. (2000). La invención de lo cotidiano I. Artes de hacer. México: Universidad Iberoamericana.

Frenkel, E. (2015). Roberto Arlt\& Goya: crônicas e gravuras à água-forte, Florianópolis: Editora da UFSC.

Fritzsche, P. (2008). Berlín 1900. Prensa, lectores y vida moderna. Buenos Aires: Siglo XXI.

Gilman, C. (2006). Florida y Boedo: hostilidades y acuerdos. Montaldo, G. (Comp.) y Viñas, D. (Dir.) Yrigoyen entre Borges y Arlt (1916-1930): literatura argentina siglo XX, Buenos Aires: Paradiso.

González Tuñón, R. (1972). El violín del diablo. Buenos Aires: Ediciones la Rosa blindada.

Gorelik, A. (2013). Miradas sobre Buenos Aires: Historia cultural y crítica urbana. Buenos Aires: Siglo Veintiuno Editores.

Gorelik, A. (2016). La grilla y el parque: espacio público y cultura urbana en Buenos Aires 1887-1936. Bernal: Universidad Nacional de Quilmes.

López Anaya, J. (1997). Historia del arte argentino. Buenos Aires: Emecé.

Montaldo, G. (1993). De pronto, el campo. Literatura y tradición rural. Rosario: Beatriz Viterbo Editora.

Orgambide, P. (2000). La modernidad de lo real. En: AA.VV Pintura Argentina- Panorama del período 1810-2000.

Spilimbergo y Guttero, Argentina: Ediciones Banco Velox, pp. 5-6.

Porrúa A. (2011). Caligrafía tonal: ensayos sobre poesía. Buenos Aires: Entropía.

Prieto, M. (2006). Breve historia de la literatura argentina. Buenos Aires: Taurus.

Ramos, J. (1989). Desencuentros de la modernidad en América Latina, México: Fondo de Cultura Económica.

Rancière, J. (2010). El espectador emancipado. Buenos Aires: Manantial.

Ramos, J. (1989). Desencuentros de la modernidad en América Latina. México: FCE.

Saítta, S. (2008). El escritor en el bosque de ladrillos. Buenos Aires: Debolsillo.

Sarlo, B. (1988).Una modernidad periférica: Buenos Aires 1920 y 1930. Buenos Aires: Nueva Visión.

Sarlo, B. (1992). La imaginación técnica. Buenos Aires: Nueva Visión.

Scobie, J. R. y De Luzzi A.R. (2000). El puerto y los ferrocarriles. En: Romero J.L. y Romero L. A. (Edit.). Buenos Aires, Historia de cuatro siglos. Tomo II (pp. 22-24) Buenos Aires: Altamira.

Silvestri, G. (1993). La ciudad y el río. En: Liernur, J. y Silvestri, G. El umbral de la metrópolis. Transformaciones técnicas y cultura en la modernización de Buenos Aires (1870-1930) (pp-97-176) Buenos Aires: Editorial Sudamericana.

Silvestri, G. y Aliata, F. (2001). El paisaje como cifra de armonía. Buenos Aires: Ediciones Nueva Visión.

Silvestri, G. (2012). El color del río. Historia cultural del paisaje del Riachuelo. Bernal: Universidad Nacional de Quilmes.

Wechsler, Diana (2010). "Impacto y matices de una modernidad en los márgenes. Las artes plásticas entre 1920 y 1945". En Burucúa, J.E. (Ed.), Nueva Historia argentina. Arte, sociedad y política (pp.269-312), Tomo 1. Buenos Aires: Sudamericana. 
